\title{
BMJ Open Feeding styles, parenting styles and snacking behaviour in children attending primary schools in multiethnic neighbourhoods: a cross- sectional study
}

Lu Wang, ${ }^{1}$ Vivian M van de Gaar, ${ }^{1}$ Wilma Jansen, ${ }^{1,2}$ Cathelijne L Mieloo, ${ }^{1,3}$ Amy van Grieken, ${ }^{1}$ Hein Raat $^{1}$

To cite: Wang L, van de Gaar VM, Jansen W, et al. Feeding styles, parenting styles and snacking behaviour in children attending primary schools in multiethnic neighbourhoods: a crosssectional study. BMJ Open 2017;7:e015495. doi:10.1136/ bmjopen-2016-015495

- Prepublication history and additional material are available. To view these files please visit the journal online (http://dx.doi. org/10.1136/bmjopen-2016015495).

Received 20 December 2016 Revised 2 May 2017 Accepted 4 May 2017

CrossMark

${ }^{1}$ Department of Public Health, Erasmus University Medical Center, Rotterdam, The Netherlands

${ }^{2}$ Department of Social Development, Rotterdam, The Netherlands

${ }^{3}$ Municipal Public Health Service Rotterdam-Rijnmond, Rotterdam, The Netherlands

Correspondence to Dr Hein Raat; h.raat@ erasmusmc.nl

\section{ABSTRACT}

Objective The aim of the present study was to investigate whether feeding styles and parenting styles are associated with children's unhealthy snacking behaviour and whether the associations differ according to children's ethnic background.

Method Cross-sectional data from the population-based 'Water Campaign' study were used. Parents $(n=644)$ of primary school children (6-13 years) completed a questionnaire covering sociodemographic characteristics, feeding style dimensions ('control over eating', 'emotional feeding', 'encouragement to eat' and 'instrumental feeding'), parenting style dimensions ('involvement' and 'strictness') and children's unhealthy snacking behaviour. Logistic regression analyses were performed to determine whether feeding styles and parenting styles were associated with children's unhealthy snacking behaviour. Result Overall, children whose parents had a higher extent of 'control over eating' had a lower odds of eating unhealthy snacks more than once per day ( $O R$, $0.57 ; 95 \% \mathrm{Cl} 0.42$ to 0.76 ). Further stratified analysis showed that 'control over eating' was associated with less unhealthy snacking behaviour only in children with a Dutch (OR, $0.37 ; 95 \% \mathrm{Cl} 0.20$ to 0.68 ) or a Moroccan/ Turkish (OR, $0.44 ; 95 \% \mathrm{Cl} 0.25$ to 0.77 ) ethnic background. 'Encouragement to eat' was associated with a lower odds of eating unhealthy snacks every day in children with a Dutch ethnic background only (OR, $0.48 ; 95 \% \mathrm{Cl} 0.25$ to 0.90). 'Instrumental feeding' was associated with a higher odds of eating unhealthy snacks more than once a day in children with a Moroccan/Turkish ethnic background only (0R, 1.43; 95\% Cl 1.01 to 2.04).

Conclusion Our results suggest that 'control over eating' may be associated with less unhealthy snack consumption in children. The associations of feeding styles and parenting styles with children's unhealthy snacking behaviour differed between children with different ethnic backgrounds.

\section{INTRODUCTION}

A high intake of unhealthy snack foods that is, snack foods high in fat, sugar and salt but low in micronutrients - is known to
Strengths and limitations of this study

- Our data were collected from an ethnically diverse study population.

- Validated questionnaires were used to measure feeding styles and parenting styles, which allowed comparisons with other studies.

- We relied on parents' self-reports for children's unhealthy snacking behaviour, and social desirability and recall bias could have been possible.

- This study does not allow firm conclusions with regard to causality due to the observational nature of cross-sectional design.

have adverse health outcomes (eg, obesity, metabolic syndrome and dental caries). ${ }^{1-4}$ Studies performed among children living in both developed and low-income/middle-income countries showed that the consumption of unhealthy snack foods among children has largely increased during the past few decades. ${ }^{5-10}$ According to the 2007-2010 Netherlands' national food consumption survey, children aged 7- to 12 years had an average of 3.3 events during the day eating energy-dense snack foods, with $90 \%$ of children consuming more energy from unhealthy snack foods than is recommended (837-1255 $\mathrm{kJ}$ per day). ${ }^{11}$ Given that snacking habits are established during childhood and often persist into adulthood, ${ }^{12}$ unhealthy snacking behaviour should be discouraged at an early age.

Parents play an important role in shaping children's eating behaviours, through feeding styles and parenting styles. ${ }^{13-19}$ Parental feeding styles can be measured using the Parental Feeding Style Questionnaire (PFSQ). ${ }^{20}$ This measure assesses four commonly used aspects of parental feeding, 
namely 'control over eating' (controlling the child's food intake), ${ }^{13} 15$ 'encouragement to eat' (encouraging the child to eat a variety of foods), ${ }^{1415}$ 'instrumental feeding' (using food as a reward) and 'emotional feeding' (offering food to soothe the child's negative emotions).$^{20}$ Previous studies have indicated that 'control over eating ${ }^{13} 15$ and 'encouragement to eat' are associated with lower child unhealthy snack intake, while 'instrumental feeding' and 'emotional feeding' have been associated with a higher unhealthy snack intake among children. ${ }^{13-15}$

Parenting style can be defined as a constellation of attitudes and beliefs towards the child that create an emotional climate in which parents' behaviours are expressed. ${ }^{21}$ Based on variations in two parenting dimensions 'involvement' (also called responsiveness) and 'strictness' (also called demandingness) - four parenting styles can be defined: authoritative, authoritarian, indulgent and neglectful. ${ }^{21} 22$ In general, an authoritative parenting style is characterised by high involvement and high strictness and is associated with healthier dietary behaviours of the child, ${ }^{17182324}$ including lower unhealthy snack intake. ${ }^{16}$

To date, only limited studies have investigated the associations of feeding styles and parenting styles with children's unhealthy snacking behaviour. The majority of these studies have focused on native European populations. ${ }^{14-16}$ The impact of parental feeding styles and parenting styles may differ by ethnic subgroups. ${ }^{25-31}$ For instance, a study in the USA indicated that among children with Hispanic background, parental 'emotional feeding' and 'instrumental feeding' predicted increased child sweet beverage consumption. ${ }^{32}$ However, among children with an Afro-American background, this study observed no association between parental feeding styles and child sweet beverage consumption. ${ }^{32}$ In the Netherlands, to the best of our knowledge, thus far no study has been published evaluating differences in feeding styles or parenting styles among groups with differential ethnic background. With regard to the development of interventions in ethnically diverse populations, it is important to study the differential influence of feeding styles and parenting styles on children's unhealthy snack consumption in each ethnic subgroup separately.

Therefore, the aim of the present study was to determine whether feeding styles and parenting styles are associated with children's unhealthy snacking behaviour, and to explore whether the associations differ according to the children's ethnic background. We hypothesised that (1) 'control over eating' and 'encouragement to eat' were associated with less unhealthy snacking behaviour among children, (2) 'instrumental feeding' and 'emotional feeding' were associated with more unhealthy snacking behaviour among children, and (3) an authoritative parenting style was associated with less unhealthy snacking behaviour among children. In addition, we hypothesised that the associations of feeding styles and parenting styles with child unhealthy snacking behaviour differed between distinct ethnic subgroups.

\section{MATERIALS AND METHODS}

\section{Study population}

Our cross-sectional study used baseline data from the population-based 'Water Campaign' study. ${ }^{33}$ This controlled trial assessed the effects of a combined schoolbased and community-based intervention on children's sugar-sweetened beverages consumption. Four primary schools located in disadvantaged multiethnic neighbourhoods in Rotterdam, the Netherlands, were included in the study. The 'Water Campaign' study is an extension of the municipal overweight intervention programme 'Enjoy being Fit'. ${ }^{4}$

At the participating schools, all children in grades 2-8 (1288 children, aged 6-13 years) were invited to participate. Passive parental consent was obtained; parents (and children) were informed about the intervention and the study and were free to refuse participation without giving any explanation (reference number MEC-2011-183).

Measurements were performed at baseline and after 1 year using questionnaires (child and parental) and observations at school. The questionnaires were shown to be feasible during pretesting in a comparable population before the start of the study. Parents of all children in grades 2-8 (aged 6-13 years) at participating schools received the baseline questionnaires on paper from the teachers. The parental questionnaire could be completed at home by the main caregiver of the child, within a period of maximum 4 weeks. ${ }^{33}$ For the present study, data from the baseline parental questionnaire (administered March/April 2011) were used. A study population of 644 parent-child dyads were available for analyses.

\section{Measures}

\section{Sociodemographic characteristics}

The sociodemographic characteristics of the child were assessed using the parental questionnaire: age (years), gender (boy/girl) and ethnic background. The child's ethnic background was based on the country of birth of the parents, according to definitions given by Statistics Netherlands. ${ }^{35}$ The child's ethnic background was Dutch only if both parents had been born in the Netherlands; if one of the parents had been born in another country, then the ethnic background of the child was defined according to that country. If both of the parents had been born in other countries, the ethnic background of the child was defined according to the mother's country of birth. ${ }^{35}$ The ethnic background of the child was categorised as Dutch, Surinamese/Antillean, Moroccan/ Turkish or other. ${ }^{33}$ Children categorised to the 'other' subgroup were of mixed ethnic background, such as German or Cape-Verdean. Respondents were either the father or the mother of the child, and parental gender was based on this item (male/female). Parental age (years) and educational level were also reported. According to the standard Dutch cut-off points, the educational level of the responding parent was categorised as 'low' (no education; primary school; $\leq 3$ years of general secondary school), 'mid-low' (>3 years of general secondary school), 
'mid-high' (higher vocational training; undergraduate programmes) or 'high' (higher academic education). ${ }^{36}$ Respondents reported whether the child lived with both parents versus single parent, and how many siblings the child had.

\section{Weight status of the child}

The child's height and weight were measured in light clothing without shoes by trained personnel, according to the Youth Health Care protocol. ${ }^{37}$ The child's body mass index (BMI) was calculated as weight $/\left(\right.$ height $\left.^{2}\right)$. The child's weight status was categorised as being 'non-overweight', 'overweight or obese' based on the age-specific and gender-specific BMI cut-off points published by the International Obesity Task Force. ${ }^{38}$

\section{Feeding style}

The validated Dutch version of the $\mathrm{PFSQ}^{20}$ was used to assess the four feeding style dimensions: "control over eating' (10 items), 'emotional feeding' (4 items), 'instrumental feeding' (5 items) and 'encouragement to eat' (8 items). Parents were asked to respond on a 5-point Likert scale ranging from 'never' ( 1 point) to 'always' (5 points). Average scores on each scale were calculated for each parent, and the score was considered as missing if $50 \%$ or more of the items of the scale were missing. The percentage of parents with any missing item ranged from $4.6 \%$ to $10.1 \%$ for the four scales (see online supplementary table $\mathrm{S} 1$ ). There was no difference in the percentage of parents with any missing item or with $50 \%$ or more missing items between ethnic subgroups $(p>0.05)$. In addition we did a sensitivity analysis using complete cases only, and the results were comparable (data not shown). A higher score indicated a greater tendency for parents to apply a specific feeding style. In the present study, the Cronbach's $\alpha$ was 0.78 for the 'control over eating' scale, 0.87 for the 'emotional feeding' scale, 0.79 for the 'instrumental feeding' scale and 0.77 for the 'encouragement to eat' scale.

\section{Parenting style}

The validated Dutch version of the Steinberg parenting style instrument ${ }^{39-41}$ was used to measure the two parenting style dimensions: 'involvement' and 'strictness'. The 'involvement' scale contains nine items that assess indicators of parental loving, responsiveness and involvement (eg, 'My child can count on me when he or she has some kind of problem'). The 'strictness' scale contains six items that assess parental monitoring and supervision of the child (eg, 'I know what my child does in his or her free time'). Parents were asked to respond on a 5-point Likert scale ranging from 'strongly disagree' ( 1 point) to 'strongly agree' ( 5 points). Average scores on each scale were calculated for each parent, and the score was considered as missing if $50 \%$ or more of the items of the scale were missing. The percentage of parents with any missing item was $7.1 \%$ and $10.1 \%$ for the involvement and strictness scale, respectively (see online supplementary table $\mathrm{S} 1$ ). There was no difference in the percentage of parents with $50 \%$ or more missing items between ethnic subgroups $(p>0.05)$. In addition we did a sensitivity analysis using complete cases only, and the results were comparable (data not shown). Based on the median split of both scales, ${ }^{40}$ the dimensions of parenting style were further defined into the following categories: authoritative (high involvement and high strictness), authoritarian (low involvement and high strictness), indulgent (high involvement and low strictness) and neglectful (low involvement and low strictness).

\section{Unhealthy snacking behaviour of the child}

Two items in the parental questionnaire were used to assess children's unhealthy snacking behaviour. The questionnaire items were based on previously used questionnaires, mainly used in earlier Dutch studies. ${ }^{42}{ }^{43} \mathrm{In}$ the present study, unhealthy snacks were defined as energy-dense nutrient-poor foods eaten between the three main meals. Parents were provided with the following examples of unhealthy snacks: crisps, nuts, chocolate, Mars bars, pastry, iced cake, ice cream, pizza, meatballs and burgers. Parents reported how many days in a normal week the child ate unhealthy snacks (response categories: 'every day' and 'not every day') and the frequency of eating unhealthy snacks on such a day (response categories ranged from 'none', ' 1 per day' to ' 5 or more per day'). The frequency of eating unhealthy snacks per day was dichotomised into ' $\leq 1$ snack per day' and ' $>1$ snack per day'.

\section{Statistical analysis}

Descriptive statistics were used to present the demographic characteristics of the children and the responding parents. Differences in demographic characteristics between subgroups according to the child's ethnic background were compared using analysis of variance or Kruskal-Wallis test for continuous variables and a $\mathrm{X}^{2}$ test for categorical variables.

Logistic regression analyses were used to investigate whether feeding styles and parenting styles were associated with the children's unhealthy snacking behaviour. Unhealthy snacking behaviour of the child was assessed using two variables: unhealthy snacks every day (yes/ no) and unhealthy snack frequency per day ( $\leq 1$ or $>1$ per day). Descriptive results of the dimensions of feeding style, dimensions of parenting style and the parenting style categories according to child snacking behaviour are presented in online supplementary table S2). Separate logistic regression models were built for each dimension of feeding style, dimension of parenting style and parenting style categories, adjusted for potential confounders. In order to select potential confounders, we used logistic and general linear regression to examine the associations between potential confounders and children's unhealthy snacking behaviour and dimensions of feeding style, dimensions of parenting style and parenting style categories. Factors were considered as potential confounders if 
they were associated with both the children's unhealthy snacking behaviour and any of the dimensions of feeding style, dimensions of parenting style and parenting style categories. The following factors were evaluated as potential confounders: responding parents' age, gender, education level, weight status, and single parent versus both parents, and child age, gender, weight status and number of siblings.

To examine whether the associations between dimensions of feeding style, dimensions of parenting style, parenting style categories and the children's unhealthy snacking behaviour differed according to the children's ethnic background, an interaction term of the independent variable with child ethnic background was added to the model. The interaction term was considered significant at a level of $\mathrm{p}<0.100 .{ }^{44}$ The logistic regression models were repeated for subgroups of children with a Dutch, Surinamese/Antillean, Moroccan/Turkish and other ethnic background, respectively. Assuming a random missing pattern of data, complete subject analyses were chosen to handle the missing values. ${ }^{45}$ All analyses were conducted using the statistical software SAS V.9.3.

\section{RESULTS}

\section{Characteristics of the study population}

The characteristics of the children and parents are shown in table 1, which presents data from the overall sample as well as for each subgroup based on the children's ethnic background. The mean age of the children in our study was 9.4 (SD 1.8) years; $45.9 \%$ of them were boys and $30.3 \%$ had a Dutch ethnic background. Based on the parents' report, $14.6 \%$ of the children ate unhealthy snacks on a daily basis, and $29.7 \%$ ate unhealthy snacks more than once a day. The mean age of the responding parents was 37.9 (SD 7.4), $87.4 \%$ of them were mothers and $18.5 \%$ indicated having completed a high level of education.

Overall, the scores for all the dimensions of feeding styles, parenting style and parenting style categories were different between the ethnic subgroups $(p<0.05)$ (table 2). In addition, post-hoc analysis showed that parents of children with a Dutch ethnic background reported using the highest levels of 'control over eating' and 'encouragement to eat', but the lowest levels of 'instrumental feeding' and 'emotional feeding' $(p<0.05)$. Parents of children with a Surinamese/Antillean ethnic background had similar levels of 'encouragement to eat', 'instrumental feeding' and 'emotional feeding' compared with parents of children with a Dutch ethnic background, but a lower level of 'control over eating' $(p<0.05)$. Parents of children with a Moroccan/Turkish ethnic background reported using the highest levels of 'instrumental feeding' and 'emotional feeding' $(p<0.05)$. With regard to the dimensions of parenting style, the levels of parental 'involvement' and 'strictness' were similar between parents of children with a Dutch, Surinamese/ Antillean and Moroccan/Turkish ethnic background ( $>0.05)$. Parents of children with Surinamese/Antillean ethnic background used 'authoritarian' parenting style less often than as Dutch parents did $(\mathrm{p}<0.05)$.

Associations between dimensions of feeding style, parenting style, parenting style categories and children's unhealthy snacking behaviour

Table 3 presents the associations between dimensions of feeding style, dimensions of parenting style and parenting style categories and children's unhealthy snacking behaviour. With regard to the dimensions of feeding style, children whose parents had a higher score on 'control over eating' had a lower odds of eating unhealthy snacks every day (OR $0.63 ; 95 \%$ CI 0.44 to 0.91 ) and of eating unhealthy snacks more than once per day (OR 0.57 ; $95 \%$ CI 0.42 to 0.76 ). With regard to the dimensions of parenting style, no significant association was observed for neither the 'involvement' nor the 'strictness' dimension with children's unhealthy snacking behaviour. Children of parents having an 'indulgent' parenting style were less likely to eat unhealthy snacks every day (OR $0.25 ; 95 \%$ CI 0.09 to 0.73 ) compared with children of parents using an 'authoritative' parenting style.

\section{Analyses according to the children's ethnic background}

Table 4 shows the associations of dimensions of feeding style, dimensions of parenting style and parenting style categories with children's unhealthy snacking behaviour according to the children's ethnic background. With regard to feeding style dimensions, a higher score on the 'control over eating' was associated with a lower possibility of eating unhealthy snacks every day for children with a Dutch ethnic background (OR 0.41; 95\% CI 0.21 to 0.79 ) and for children with a Moroccan/Turkish ethnic background (OR 0.40; 95\% CI 0.19 to 0.88 ). A higher score on the 'encouragement to eat' was associated with lower possibility of eating unhealthy snacks every day for children with Dutch ethnic background only (OR $0.48 ; 95 \%$ CI 0.25 to 0.90 ). In addition, a higher score on the 'control over eating' was associated with a lower possibility of eating unhealthy snacks more than once per day for children with a Dutch ethnic background (OR 0.37; 95\% CI 0.20 to 0.68 ) and for children with a Moroccan/Turkish ethnic background (OR 0.44; $95 \%$ CI 0.25 to 0.77 ). Finally, 'instrumental feeding' was associated with a higher possibility of eating unhealthy snacks more than once per day for children with a Moroccan/Turkish ethnic background only (OR 1.43; 95\% CI 1.01 to 2.04 ).

With regard to parenting style dimensions, a higher score on parental 'involvement' was associated with a lower possibility of eating unhealthy snacks every day in children with an 'other' ethnic background (OR 0.21; $95 \%$ CI 0.08 to 0.59 ). Children with an 'other' ethnic background whose parents had a 'neglectful' parenting style were more likely to eat unhealthy snacks more than once a day (OR 2.78; 95\% CI 1.05 to 7.33) compared with children from parents who had an 'authoritative' parenting style. 


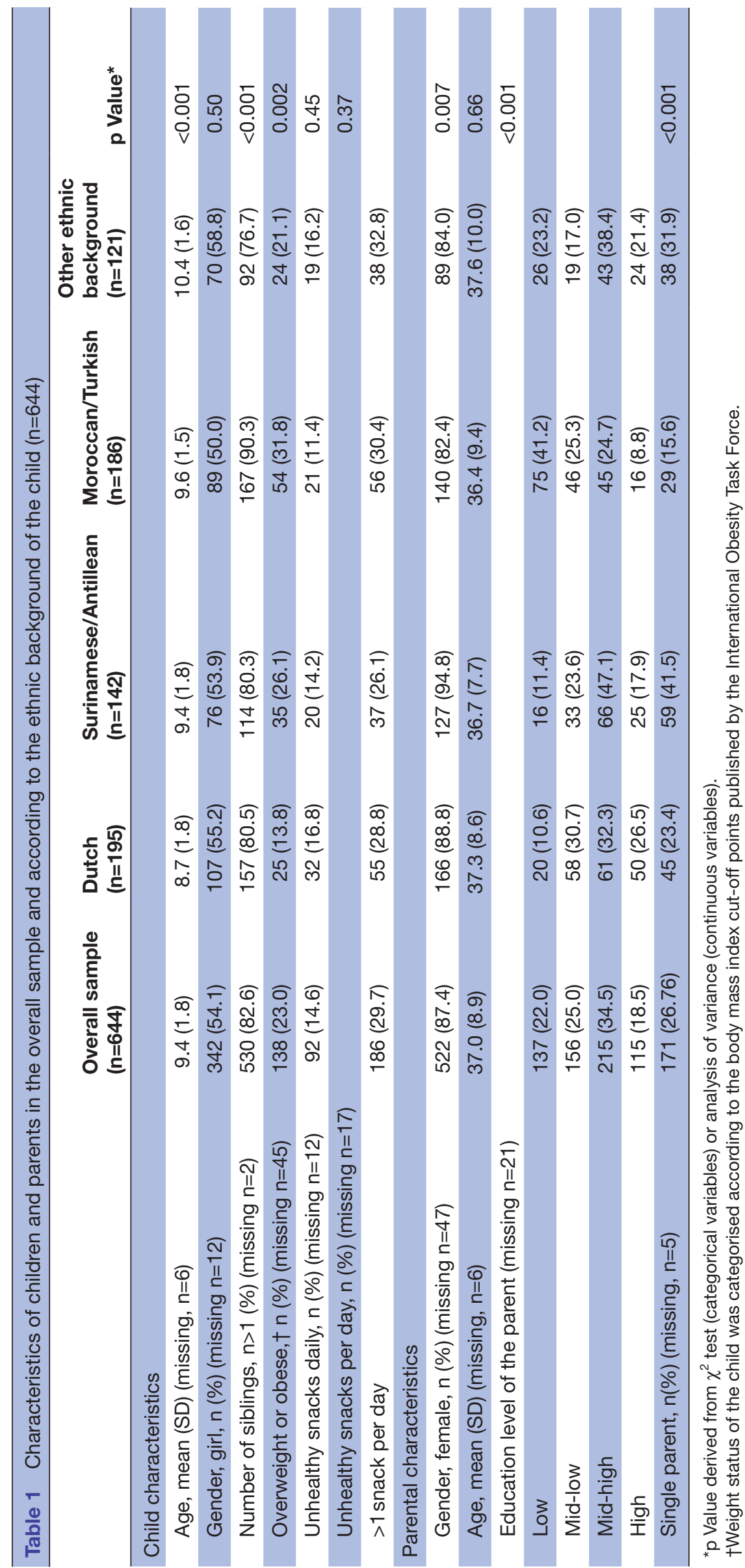

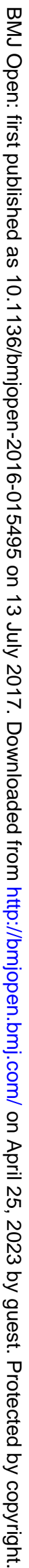


Table 2 Average scores on feeding style dimensions, parenting style dimensions and parenting style categories according to the children's ethnic background $(n=644)$

\begin{tabular}{|c|c|c|c|c|c|}
\hline & $\begin{array}{l}\text { Dutch } \\
(n=195)\end{array}$ & $\begin{array}{l}\text { Surinamese/Antillean } \\
(n=142)\end{array}$ & $\begin{array}{l}\text { Moroccan/Turkish } \\
(n=186)\end{array}$ & $\begin{array}{l}\text { Other ethnic } \\
\text { background } \\
\text { ( } n=121)\end{array}$ & p Value \\
\hline \multicolumn{6}{|c|}{ Feeding style dimensions, mean (SD) } \\
\hline Control over eating & $4.03(0.55)$ & $3.72(0.63)$ & $3.76(0.58)$ & $3.56(0.72)$ & $<0.001$ \\
\hline Emotional feeding & $1.58(0.66)$ & $1.58(0.60)$ & $2.02(0.87)$ & $2.03(0.94)$ & $<0.001$ \\
\hline Encouragement to eat & $3.86(0.62)$ & $3.80(0.69)$ & $3.74(0.66)$ & $3.72(0.67)$ & 0.03 \\
\hline Instrumental feeding & $1.93(0.78)$ & $1.90(0.77)$ & $2.56(0.91)$ & $2.28(0.93)$ & $<0.001$ \\
\hline \multicolumn{6}{|c|}{ Parenting style dimensions, mean (SD) } \\
\hline Involvement & $4.58(0.33)$ & $4.65(0.36)$ & $4.55(0.42)$ & $4.48(0.51)$ & 0.02 \\
\hline Strictness & $4.58(0.58)$ & $4.52(0.63)$ & $4.50(0.57)$ & $4.41(0.71)$ & 0.03 \\
\hline \multicolumn{6}{|c|}{ Parenting style categories, $\mathrm{n}(\%)$} \\
\hline Authoritative & $70(37.63)$ & $66(47.83)$ & $67(37.43)$ & $40(34.78)$ & 0.007 \\
\hline Authoritarian & $36(19.35)$ & $8(5.80)$ & $16(8.94)$ & $15(13.04)$ & \\
\hline Indulgent & $25(13.44)$ & $21(15.22)$ & $27(15.08)$ & $13(11.30)$ & \\
\hline Neglectful & $55(29.57)$ & $43(31.16)$ & $69(38.55)$ & $47(40.87)$ & \\
\hline
\end{tabular}

$\mathrm{p}$ Value derived from Kruskal-Wallis test (feeding style dimensions and parenting style dimensions) or $\chi^{2}$ test (parenting style categories).

\section{DISCUSSION}

In this study, we investigated the associations of dimensions of feeding style, dimensions of parenting style and parenting style categories with unhealthy snack consumption in school-aged children from a multiethnic population. In line with our hypothesis, 'control over eating' was associated with lower unhealthy snacking behaviour of the child. We did not observe significant associations between 'encouragement to eat', 'instrumental feeding' and 'emotional feeding' and child unhealthy snacking behaviour. Also, no association between an 'authoritative' parenting style and child

Table 3 Results of the logistic regression analyses for the associations of feeding style dimensions, parenting style dimensions and parenting style categories with children's unhealthy snacking behaviour $(n=644)$

\begin{tabular}{|c|c|c|c|c|}
\hline \multirow[b]{2}{*}{ Variables } & \multicolumn{2}{|c|}{$\begin{array}{l}\text { Unhealthy snacks every day } \\
\text { (yes vs no) }\end{array}$} & \multicolumn{2}{|c|}{$\begin{array}{l}\text { Unhealthy snack frequency per day } \\
(>1 \text { vs } \leq 1)\end{array}$} \\
\hline & $\begin{array}{l}\text { Unadjusted* OR } \\
(95 \% \mathrm{Cl})\end{array}$ & $\begin{array}{l}\text { Adjusted†OR } \\
(95 \% \mathrm{Cl})\end{array}$ & $\begin{array}{l}\text { Unadjusted }{ }^{*} \text { OR } \\
(95 \% \mathrm{Cl})\end{array}$ & $\begin{array}{l}\text { Adjusted†OR } \\
(95 \% \mathrm{Cl})\end{array}$ \\
\hline \multicolumn{5}{|l|}{ Feeding style dimensions } \\
\hline Control over eating & $0.63(0.45$ to 0.88$)$ & $0.63(0.44$ to 0.91$)$ & 0.54 (0.41 to 0.71$)$ & 0.57 (0.42 to 0.76$)$ \\
\hline Emotional feeding & 0.92 (0.69 to 1.23$)$ & 0.95 (0.69 to 1.30$)$ & 1.24 (1.01 to 1.53$)$ & 1.18 (0.93 to 1.48$)$ \\
\hline Encouragement to eat & 0.80 (0.57 to 1.11$)$ & 0.73 (0.52 to 1.04$)$ & 0.87 (0.67 to 1.13$)$ & 0.97 (0.73 to 1.28$)$ \\
\hline Instrumental feeding & 0.92 (0.71 to 1.19$)$ & 0.92 (0.69 to 1.22$)$ & 1.10 (0.90 to 1.33$)$ & 0.99 (0.80 to 1.23$)$ \\
\hline \multicolumn{5}{|l|}{ Parenting style dimensions } \\
\hline Involvement & $0.56(0.33$ to 0.93$)$ & 0.60 (0.35 to 1.04$)$ & 0.68 (0.45 to 1.04$)$ & 0.78 (0.50 to 1.21$)$ \\
\hline Strictness & 1.23 (0.83 to 1.82$)$ & 1.43 (0.92 to 2.21$)$ & 0.80 (0.61 to 1.05$)$ & 0.89 (0.66 to 1.20$)$ \\
\hline \multicolumn{5}{|l|}{ Parenting style categories } \\
\hline Authoritative & Ref & Ref & Ref & Ref \\
\hline Authoritarian & 1.14 (0.57 to 2.27$)$ & 1.10 (0.53 to 2.28$)$ & 1.20 (0.68 to 2.11$)$ & 1.31 (0.72 to 2.38 ) \\
\hline Indulgent & $0.26(0.09$ to 0.76$)$ & 0.25 (0.09 to 0.73$)$ & 0.90 (0.51 to 1.60$)$ & 0.87 (0.48 to 1.56$)$ \\
\hline Neglectful & 0.94 (0.57 to 1.57$)$ & 0.84 (0.48 to 1.46$)$ & 1.33 (0.89 to 1.98$)$ & 1.21 (0.78 to 1.87$)$ \\
\hline
\end{tabular}

Numbers printed in bold represent a significant association at $p<0.05$ between the independent variable and children's unhealthy snacking behaviour.

${ }^{*}$ Results from separate logistic regression models for each independent variable, without adjusting for potential confounders.

†Results from separate logistic regression models for each independent variable, adjusted for the child's age, weight status, ethnic background and the responding parent's education level. 
Table 4 Results of the logistic regression analyses for the associations of feeding style dimensions, parenting style dimensions and parenting style categories with the children's unhealthy snacking behaviour, stratified by the children's ethnic background

\begin{tabular}{|c|c|c|c|c|}
\hline & $\begin{array}{l}\text { Dutch } \\
n=195\end{array}$ & $\begin{array}{l}\text { Surinamese/ } \\
\text { Antillean } \\
n=142\end{array}$ & $\begin{array}{l}\text { Moroccan/Turkish } \\
n=186\end{array}$ & $\begin{array}{l}\text { Other ethnic } \\
\text { background } \\
n=121\end{array}$ \\
\hline & OR $(95 \% \mathrm{Cl})^{*}$ & OR $(95 \% \mathrm{Cl})^{*}$ & OR $(95 \% \mathrm{Cl})^{*}$ & OR $(95 \% \mathrm{Cl})^{*}$ \\
\hline \multicolumn{5}{|l|}{ Unhealthy snacks every day } \\
\hline \multicolumn{5}{|l|}{ Feeding style dimensions } \\
\hline Control over eating $\dagger$ & $0.41(0.21$ to 0.79$)$ & $1.17(0.52$ to 2.64$)$ & $0.40(0.19$ to 0.88$)$ & $0.66(0.33$ to 1.31$)$ \\
\hline Emotional feeding & 1.13 (0.64 to 2.00$)$ & 0.50 (0.18 to 1.35$)$ & 1.01 (0.60 to 1.71$)$ & 0.93 (0.53 to 1.61$)$ \\
\hline Encouragement to eat & $0.48(0.25$ to 0.90$)$ & 1.17 (0.56 to 2.47$)$ & $1.05(0.52$ to 2.11$)$ & $0.71(0.35$ to 1.45$)$ \\
\hline Instrumental feeding & 1.10 (0.68 to 1.80$)$ & 0.79 (0.40 to 1.56$)$ & 1.13 (0.69 to 1.85$)$ & 0.71 (0.40 to 1.28$)$ \\
\hline \multicolumn{5}{|l|}{ Parenting style dimensions } \\
\hline Involvement $†$ & $1.00(0.32$ to 3.17$)$ & 1.74 (0.39 to 7.86$)$ & 0.51 (0.18 to 1.41$)$ & $0.25(0.09$ to 0.67$)$ \\
\hline Strictness $\dagger$ & 2.04 (0.86 to 4.85$)$ & 2.60 (0.84 to 8.09$)$ & 0.92 (0.41 to 2.06$)$ & 0.67 (0.35 to 1.29$)$ \\
\hline \multicolumn{5}{|l|}{ Parenting style categories $\dagger$} \\
\hline Authoritative & Ref & Ref & Ref & Ref \\
\hline Authoritarian & 1.25 (0.48 to 3.22$)$ & $0.58(0.07$ to 5.16$)$ & 1.77 (0.31 to 10.09$)$ & 0.49 (0.05 to 4.54$)$ \\
\hline Indulgent & $-\ddagger$ & 0.20 (0.03 to 1.66$)$ & 1.55 (0.34 to 6.99$)$ & $-\ddagger$ \\
\hline Neglectful & $0.53(0.20$ to 1.40$)$ & 0.31 (0.08 to 1.18$)$ & 2.01 (0.68 to 6.51$)$ & 2.33 (0.74 to 7.33$)$ \\
\hline \multicolumn{5}{|c|}{ Unhealthy snacks $>1$ times per day } \\
\hline \multicolumn{5}{|l|}{ Feeding style dimensions } \\
\hline Control over eating $\dagger$ & $0.37(0.20$ to 0.68$)$ & $1.02(0.56$ to 1.85$)$ & $0.44(0.25$ to 0.77$)$ & $0.44(0.24$ to 0.79$)$ \\
\hline Emotional feeding & 1.18 (0.74 to 1.89$)$ & 0.84 (0.44 to 1.59$)$ & 1.29 (0.93 to 1.70$)$ & 1.56 (1.02 to 2.39$)$ \\
\hline Encouragement to eat & 0.64 (0.38 to 1.02$)$ & 0.97 (0.56 to 1.67$)$ & 1.20 (0.73 to 1.96$)$ & 0.74 (0.41 to 1.32$)$ \\
\hline Instrumental feeding $\dagger$ & $1.10(0.74$ to 1.64$)$ & 0.84 (0.5 to 1.38$)$ & 1.43 (1.01 to 2.04$)$ & 0.80 (0.52 to 1.25$)$ \\
\hline \multicolumn{5}{|l|}{ Parenting style dimensions } \\
\hline Involvement & 1.26 (0.48 to 3.29$)$ & 0.88 (0.31 to 2.49$)$ & 0.65 (0.31 to 1.37$)$ & 0.45 (0.20 to 1.02$)$ \\
\hline Strictness & $1.13(0.64$ to 2.00$)$ & 0.77 (0.43 to 1.38$)$ & 0.83 (0.48 to 1.44$)$ & 0.58 (0.33 to 1.00$)$ \\
\hline \multicolumn{5}{|l|}{ Parenting style categories } \\
\hline Authoritative & Ref & Ref & Ref & Ref \\
\hline Authoritarian & 1.79 (0.77 to 4.14$)$ & $-\ddagger$ & 1.15 (0.35 to 3.75$)$ & 0.94 (0.21 to 4.14$)$ \\
\hline Indulgent & 0.97 (0.35 to 2.68$)$ & $0.83(0.27$ to 2.61$)$ & $0.46(0.14$ to 1.51$)$ & 2.68 (0.67 to 10.73$)$ \\
\hline Neglectful & 0.64 (0.28 to 1.48$)$ & 1.03 (0.44 to 2.44$)$ & 1.62 (0.79 to 3.33$)$ & 2.78 (1.05 to 7.33 ) \\
\hline
\end{tabular}

Note: Numbers printed in bold represent a significant association between the independent variable and unhealthy snacking behaviour of the child.

${ }^{*}$ Results from separate logistic regression model adjusted for the child's age and weight status, and the parent's education level. †Interaction term between ethnic background of the child and the noted independent variable was significant $(p<0.10)$. $\ddagger$ Not available due to low sample size in these groups (see online supplementary table S2).

unhealthy snacking behaviour was observed. Our hypothesis with regard to different associations of dimensions of feeding style, dimensions of parenting style and parenting style categories with children's unhealthy snack consumption according to the ethnic background of the child was confirmed for some of the ethnic subgroups.

In line with previous studies, the present study found that children whose parents had a higher level of "control over eating' had a lower unhealthy snack consumption. ${ }^{13-15}$ Further stratified analysis showed that 'control over eating' was associated with lower unhealthy snack consumption in most of the ethnic subgroups, except for the subgroup of children with a Surinamese/Antillean ethnic background. An explanation for the lack of finding among the Surinamese/Antillean ethnic subgroup may be their compliance to their traditional dietary pattern. ${ }^{46}$ This traditional dietary pattern contains more vegetables and fruits and less unhealthy snack food. ${ }^{46}$ Therefore, parents may facilitate child's healthy snacking behaviour without having to use control over eating.

In the present study, 'encouragement to eat' was associated with a lower unhealthy snack consumption only in 
the subgroup of children with a Dutch ethnic background. It is possible that the association between 'encouragement to eat' and lower unhealthy snack consumption only exists when parents provide the child with more healthy alternative foods instead of unhealthy snack foods. Further studies examining the association between parental encouragement and children's unhealthy snack consumption should consider the potential influence of food provision.

Previous research suggested that 'emotional feeding' and 'instrumental feeding' were positively associated with children's unhealthy snack intake, ${ }^{13-15}$ while in our study the associations of 'instrumental feeding' and 'emotional feeding' with children's unhealthy snack intake only existed among children with a Moroccan/Turkish ethnic background and in children with an 'other' ethnic background. In addition, our study results showed that parents of children with a Moroccan/Turkish ethnic background were also more likely to apply, that is, scored higher on these dimensions, 'instrumental feeding' and 'emotional feeding', compared with the Dutch, Surinamese/Antillean and other ethnic background subgroups. These findings combined are comparable to previous findings indicating that parents mainly offer unhealthy snack food in the context of 'emotional' and 'instrumental' feeding styles. ${ }^{47}$ As a consequence hereof, using snacks as a reward may increase children's preference for the rewarding snack. ${ }^{48}$ Consequently, higher exposure together with increased preference for the unhealthy snack food may contribute to an increased risk of high unhealthy snack intake among children. Therefore, further interventions should discourage the use of 'instrumental feeding' and 'emotional feeding' in parents of children with a Moroccan/Turkish ethnic background.

Although previous studies suggested that having an 'authoritative' parenting style was associated with lower unhealthy snack consumption of children, we found no association between this parenting style category and children's unhealthy snack consumption. The lack of association might be due to the low variability on the scores of both the 'involvement' and 'strictness' dimensions among parents. Only in the subgroup of children with an 'other' ethnic background a 'neglectful' parenting style, which is characterised by low 'involvement' and low 'strictness', was associated with a higher unhealthy snack consumption. This observation of an association between having a neglectful parenting style and more unhealthy snacking behaviour is in line with previous research. ${ }^{16}{ }^{17}$ However, the contribution of ethnic background in this association is difficult to explain due to the diverse population (ie, children with mixed ethnic background) within this subgroup.

Our study suggests that the associations of feeding style dimensions, parenting style dimensions and parenting style categories with child unhealthy snack consumption differed according to the ethnic background of the child. Moreover, the findings suggest differences between subgroups in the appliance of the different feeding styles and parenting styles. Differences in parental beliefs, knowledge practices (eg, modelling, food provision) and children's food preferences between ethnic subgroups ${ }^{2527}$ may contribute to these differential applications and associations. We recommend conducting further qualitative and quantitative research to gain more insight in these ethnic group differences in associations between feeding styles and children's snacking behaviour. Increased understanding may be helpful in developing tailored interventions for reducing unhealthy snack consumption in different ethnic subgroups.

The main strengths of our study include the ethnically diverse study population, which enabled us to analyse the associations of feeding styles and parenting styles with children's unhealthy snacking behaviours in different ethnic subgroups, and the use of validated questionnaires, which allowed comparisons with other studies. Several limitations of this study should be noted. First, as we relied on parents' self-reports for the child's snack consumption, social desirability and recall bias could have been possible. Parental reports have shown to be an accurate method to estimate dietary intake in school-aged children. ${ }^{49}$ However, further studies may include a combination of parental report, child report and observational measures to estimate the child's snacking behaviour. In addition, the questionnaires were provided in Dutch only, which could have been a barrier for some parents given the diverse ethnicity of our study population. We did not collect data related to language spoken; however, parents in all ethic subgroups were living in the Netherlands for, on average, over 20 years, indicating a familiarity with the Dutch language and culture (data not shown). Second, performing stratified analysis reduced our sample size and therewith power to detect differences. Finally, given the observational nature of cross-sectional design, this study does not allow firm conclusions with regard to causality.

\section{CONCLUSION}

Our results suggest that 'control over eating' may be associated with less unhealthy snack consumption in children. The associations of feeding styles and parenting styles with children's unhealthy snacking behaviour differ among children with different ethnic background. However, due to the limitations of cross-sectional design, future longitudinal studies with larger sample sizes are recommended. In the mean time, to improve the effectiveness of interventions focusing on parenting behaviours to reduce unhealthy snacking of children, developers should take into account the potential role of children's ethnic background.

Contributors HR and WJ had the original idea for the study and its design, and were responsible for acquiring the study grant. VMvdG further developed the study protocol and is responsible for data collection. LW did the data analysis and reported the results. All authors (LW, VMvdG, AvG, CLM, WJ, HR) were involved in writing the paper and had final approval of the submitted manuscript. This study is part of the Dutch project CIA0, which stands for Consortium Integrated Approach Overweight. 
Funding This study is part of the Dutch project CIAO, which stands for Consortium Integrated Approach Overweight. This study is funded by a grant from the major funding body ZonMw (the Netherlands Organization for Health Research and Development) project no.200100001. The publication of this study was supported by a grant of the Netherlands Organization for Scientific Research (NWO).

\section{Competing interests None declared.}

Patient consent We did not include patients in the present study. Our study subjects were children attending primary schools, and their parents. Passive parental consent was obtained; parents (and children) were informed about the intervention and the study and were free to refuse participation without giving any explanation (reference number MEC-2011-183).

Ethics approval Medical and Ethical Review Committee of the Erasmus Medical Center study (reference number MEC-2011-183).

Provenance and peer review Not commissioned; externally peer reviewed.

Data sharing statement Data are available by emailing the corresponding author at h.raat@erasmusmc.nl.

Open Access This is an Open Access article distributed in accordance with the Creative Commons Attribution Non Commercial (CC BY-NC 4.0) license, which permits others to distribute, remix, adapt, build upon this work non-commercially, and license their derivative works on different terms, provided the original work is properly cited and the use is non-commercial. See: http://creativecommons.org/ licenses/by-nc/4.0/

(c) Article author(s) (or their employer(s) unless otherwise stated in the text of the article) 2017. All rights reserved. No commercial use is permitted unless otherwise expressly granted.

\section{REFERENCES}

1. Bellisle F. Meals and snacking, diet quality and energy balance. Physiol Behav 2014;134:38-43.

2. Mirmiran P, Bahadoran Z, Delshad H, et al. Effects of energy-dense nutrient-poor snacks on the incidence of metabolic syndrome: a prospective approach in Tehran lipid and glucose study. Nutrition 2014;30:538-43.

3. Who J, Consultation F. Diet, nutrition and the prevention of chronic diseases. World Health Organ Tech Rep Ser 2003;916:1-149.

4. Chapelot $D$. The role of snacking in energy balance: a biobehavioral approach. J Nutr 2011;141:158-62.

5. Larson N, Story M. A review of snacking patterns among children and adolescents: what are the implications of snacking for weight status? Child Obes 2013;9:104-15.

6. Ford CN, Slining MM, Popkin BM. Trends in dietary intake among US 2- to 6-year-old children, 1989-2008. J Acad Nutr Diet 2013;113:35-42.

7. Juul F, Hemmingsson E. Trends in consumption of ultra-processed foods and obesity in Sweden between 1960 and 2010. Public Health Nutr 2015;18:3096-107.

8. Wang Z, Zhai F, Zhang B, et al. Trends in Chinese snacking behaviors and patterns and the social-demographic role between 1991 and 2009. Asia Pac J Clin Nutr 2012;21:253-62.

9. Duffey KJ, Pereira RA, Popkin BM. Prevalence and energy intake from snacking in Brazil: analysis of the first nationwide individual survey. Eur J Clin Nutr 2013;67:868-74.

10. Macdiarmid J, Loe J, Craig LC, et al. Meal and snacking patterns of school-aged children in Scotland. Eur J Clin Nutr 2009;63:1297-304.

11. Gevers DW, Kremers SP, de Vries NK, et al. Intake of energy-dense snack foods and drinks among dutch children aged 7-12 years: how many, how much, when, where and which? Public Health Nutr 2015:1-10.

12. Craigie AM, Lake AA, Kelly SA, et al. Tracking of obesity-related behaviours from childhood to adulthood: A systematic review. Maturitas 2011;70:266-84.

13. Lo K, Cheung C, Lee A, et al. Associations between Parental Feeding Styles and Childhood Eating Habits: a survey of Hong Kong PreSchool Children. PLoS One 2015;10:e0124753.

14. Sleddens EF, Kremers SP, De Vries NK, et al. Relationship between parental feeding styles and eating behaviours of Dutch children aged 6-7. Appetite 2010;54:30-6.

15. Rodenburg G, Kremers SP, Oenema A, et al. Associations of parental feeding styles with child snacking behaviour and weight in the context of general parenting. Public Health Nutr 2014;17:960-9.
16. Boots SB, Tiggemann M, Corsini N, et al. Managing young children's snack food intake. The role of parenting style and feeding strategies. Appetite 2015;92:94-101.

17. Pearson N, Atkin AJ, Biddle SJ, et al. Parenting styles, family structure and adolescent dietary behaviour. Public Health Nutr 2010;13:1245-53.

18. Vollmer RL, Mobley AR. Parenting styles, feeding styles, and their influence on child obesogenic behaviors and body weight. A review. Appetite 2013;71:232-41.

19. Hughes SO, Frankel LA, Beltran A, et al. Food parenting measurement issues: working group consensus report. Child Obes 2013:9:S-95--90.

20. Wardle J, Sanderson S, Guthrie CA, et al. Parental feeding style and the inter-generational transmission of obesity risk. Obes Res 2002;10:453-62.

21. Darling N, Steinberg L. Parenting style as context: An integrative model. Psychol Bull 1993;113:487-96.

22. Steinberg L, Elmen JD, Mounts NS, et al. Psychosocial maturity, and academic success among adolescents. Child development 1989:1424-36.

23. Sleddens EF, Gerards SM, Thijs C, et al. General parenting, childhood overweight and obesity-inducing behaviors: a review. Int J Pediatr Obes 2011;6:e12-e27.

24. Blissett J. Relationships between parenting style, feeding style and feeding practices and fruit and vegetable consumption in early childhood. Appetite 2011;57:826-31.

25. Sherry B, McDivitt J, Birch LL, et al. Attitudes, practices, and concerns about child feeding and child weight status among socioeconomically diverse white, Hispanic, and African-American mothers. J Am Diet Assoc 2004;104:215-21.

26. Blissett J, Bennett C. Cultural differences in parental feeding practices and children's eating behaviours and their relationships with child BMI: a comparison of Black Afro-Caribbean, White British and White German samples. Eur J Clin Nutr 2013;67:180-4.

27. Brug J, Uijtdewilligen L, van Stralen MM, et al. Differences in beliefs and home environments regarding energy balance behaviors according to parental education and ethnicity among schoolchildren in Europe: the ENERGY cross sectional study. BMC Public Health 2014;14:610.

28. Evans A, Seth JG, Smith S, et al. Parental feeding practices and concerns related to child underweight, picky eating, and using food to calm differ according to ethnicity/race, acculturation, and income. Matern Child Health J 2011;15:899-909.

29. Cardel M, Willig AL, Dulin-Keita A, et al. Parental feeding practices and socioeconomic status are associated with child adiposity in a multi-ethnic sample of children. Appetite 2012;58:347-53.

30. Varela RE, Vernberg EM, Sanchez-Sosa JJ, et al. Parenting style of Mexican, Mexican American, and Caucasian-non-Hispanic families: social context and cultural influences. J Fam Psychol 2004;18:651-7.

31. Loth KA, MacLehose RF, Fulkerson JA, et al. Eat this, not that! Parental demographic correlates of food-related parenting practices. Appetite 2013:60:140-7.

32. Lora KR, Hubbs-Tait L, Ferris AM, et al. African-American and Hispanic children's beverage intake: Differences in associations with desire to drink, fathers' feeding practices, and weight concerns. Appetite 2016;107:558-67.

33. van de Gaar VM, Jansen W, van Grieken A, et al. Effects of an intervention aimed at reducing the intake of sugar-sweetened beverages in primary school children: a controlled trial. Int J Behav Nutr Phys Act 2014;11:98.

34. Jansen W, Raat H, Zwanenburg EJ, et al. A school-based intervention to reduce overweight and inactivity in children aged 6-12 years: study design of a randomized controlled trial. BMC Public Health 2008;8:257.

35. Swertz ODP, Thijssen J, Netherlands S. Migrants in the Netherlands. Voorburg/Heerlen, Netherlands: Statistics Netherlands, 2004.

36. Netherlands S. Dutch standard classification of education 2003 Voorburg/Heerlen, Netherlands: Statistics Netherlands, 2004.

37. Bulk-Bunschoten AMW RC, Leerdam FJM, Hirasing RA. Protocol for detection of overweight in preventive youth health care. Amsterdam: VUMC, 2004

38. Cole TJ, Bellizzi MC, Flegal KM, et al. Establishing a standard definition for child overweight and obesity worldwide: international survey. BMJ 2000;320:1240.

39. Veldhuis L, van Grieken A, Renders CM, et al. Parenting style, the home environment, and screen time of 5-year-old children; the 'be active, eat right' study. PLoS One 2014;9:e88486.

40. De Bourdeaudhuij I, Te Velde SJ, Maes L, et al. General parenting styles are not strongly associated with fruit and vegetable intake and social-environmental correlates among 11-year-old children in four countries in Europe. Public Health Nutr 2009;12:259-66. 
41. Lamborn SD, Mounts NS, Steinberg L, et al. Patterns of competence and adjustment among adolescents from authoritative, authoritarian, indulgent, and neglectful families. Child Dev 1991;62:1049-65.

42. van der Horst K, Oenema A, van de Looij-Jansen P, et al. The ENDORSE study: research into environmental determinants of obesity related behaviors in Rotterdam schoolchildren. BMC Public Health 2008;8:142.

43. Veldhuis L, Struijk MK, Kroeze W, et al. 'Be active, eat right', evaluation of an overweight prevention protocol among 5-year-old children: design of a cluster randomised controlled trial. BMC Public Health 2009;9:177.

44. Rosnow RL, Rosenthal R. Statistical procedures and the justification of knowledge in psychological science. Am Psychol 1989;44:1276-84.

45. Greenland S, Finkle WD. A critical look at methods for handling missing covariates in epidemiologic regression analyses. Am J Epidemiol 1995;142:1255-64.
46. Dekker LH, Nicolaou M, van Dam RM, et al. Socio-economic status and ethnicity are independently associated with dietary patterns: the HELIUS-Dietary Patterns study. Food Nutr Res 2015;59:26317.

47. Raaijmakers LG, Gevers DW, Teuscher D, et al. Emotional and instrumental feeding practices of Dutch mothers regarding foods eaten between main meals. BMC Public Health 2014;14:171.

48. Birch LL, Birch D, Marlin DW, et al. Effects of instrumental consumption on children's food preference. Appetite 1982;3:125-34.

49. Burrows TL, Martin RJ, Collins CE. A systematic review of the validity of dietary assessment methods in children when compared with the method of doubly labeled water. J Am Diet Assoc 2010;110:1501-10. 